\title{
THE COMPARISON OF HIGH VOLTAGE X-RAY GENERATORS
}

\author{
By Lauriston S. Taylor and K. L. Tucker ${ }^{1}$
}

\section{ABSTRACT}

It is shown that when measurements are made in the customary manner, the $\mathrm{X}$-ray emission of a tube operated on two mechanical rectifiers may differ by \pm 20 per cent, although the electrical indications are the same. This also applies to quality evaluations whether of the full absorption curve, half-value layer or effective wave-length type.

Determinations of percentage depth dose do not show any such marked differences since this is a comparatively insensitive indicator. It is seen, moreover, that there is little gain in percentage depth dose in going from 160 to 200 $\mathrm{kv}$ peak; the only change of significance being in the actual $10 \mathrm{~cm}$ depth dose.

It is shown on the other hand, when the potential of three generators including constant potential is measured in "effective kilovolts," that for the same effective voltage the outputs for a given filter are all very nearly the same, both as regards intensity and quality.

\section{CONTENTS}

I. Introduction

II. Apparatus

III. Intensity measurements in air 336

IV. Quality measurements in air

V. Depth dose measurements

VI. Half-value layers and true effective wave lengths

VII. Voltage measurements

VIII. Conclusion

\section{INTRODUCTION}

In the technical and clinical use of high voltage $\mathrm{X}$ rays, a wide variety of generators have come into common use. To save strain on the X-ray tube, unidirectional voltage, obtained by mechanical or by thermionic rectifiers, is usually applied. Since the rectification characteristics of such generators differ widely, there has been considerable confusion as to their relative effectiveness in producing the desired therapeutic or technical results.

Experience in this laboratory has led us to the conclusion that, due largely to the lack of properly controlled experimental conditions, comparisons between X-ray generators which have been made in the past, are of questionable soundness. For example, we have found that a different X-ray emission, as expressed in terms of the ionization produced in air, is obtained from a given tube and generator when either the aerial system or the tube inclosure is changed.

It was decided, therefore, to make a careful comparison of several typical X-ray generators having as few variables as possible and yet under as nearly clinical operating conditions as obtainable in a labora-

1 Research associate, Radiological Research Institute. This work was started by K. L. Tucker, who, by reason of illness, was obliged to withdraw from active participation before the experimental work was complete. 
tory. For the most part, the various quantities were measured in the same units and in the same manner as in the clinic so that the results may be readily interpreted in commonly used terms.

The physical equality of X-ray beams produced by different generators, so far as concerns therapeutic application, has been shown to be based on 10 or more factors. ${ }^{2}$ Included in these are tube current, tube voltage (peak), filter, quality (H. V. L. or $\left.\lambda_{e}\right),{ }^{3}$ Röntgens per minute delivered by tube, ${ }^{4}$ and percentage depth dose. ${ }^{5}$

\section{APPARATUS}

Three generators, $A, B$, and $C$, were chosen as typical. $A$ and $B$ were rated to deliver full wave 220 to $230 \mathrm{kv}$ (peak) at $30 \mathrm{ma}$ (milliamperes). $C$ was rated to deliver $200 \mathrm{kv}$ (peak) at $10 \mathrm{ma}$. $A$ was a mechanical rectifier having a single high-tension transformer and rectifying approximately $30^{\circ}$ of the cycle. $B$ was a mechanical rectifier having a divided secondary high-tension transformer and rectifying approximately $20^{\circ}$ of the cycle. $C$ was a valve tube and condenser ripple potential generator (so-called constant potential) having a ripplage ${ }^{6}$ of only about $1.5-2$ per cent per milliampere, and hence an $\mathrm{X}$-ray emission not differing appreciably from strictly constant potential.

Any one of the three generators could be connected to the same overhead system without changing its capacitance. As will be shown, this is essential. The X-ray tube was of the Coolidge type, having thin walls. Since tubes of the same design vary slightly, a single tube was left in position for the six months during which the measurements were made. It was inclosed in a rectangular 14-inch lead box, 4 by 4 by 7 feet, having forced ventilation. Previous experience indicated that X-ray tubes operate more smoothly in unconfined space than in some of the conventional tube drums. For example, it was found that for a tube operating at $200 \mathrm{kv}$ (peak) a spacing of about 12 inches from center to ground wall produced unsteadiness, whereas an 18-inch spacing appeared sufficient to avoid such difficulty. Accordingly, we used the 24-inch spacing and had no difficulty with tube unsteadiness at voltages up to $230 \mathrm{kv}$ (peak).

Control of the tube with generators $A$ and $B$ was observed by means of a d. c. milliammeter in the high-tension circuit and a wide-

\footnotetext{
2 E. A. Pohle, Am. J. Roent., vol. 18, p. 55, 1927.

3 The half-value layer (H. V.,L.) in copper or aluminum is a measure of the "penetrating power" of an $\mathrm{X}$-ray beam. It is defined as the thickness of copper (or aluminum) which interposed in an X-ray beam reduces its intensity to one-half its initial value (as measured in terms of air ionization).

The effective wave length of an X-ray beam is the wave length of the homogeneous radiation having the same absorption coefficient in copper (or aluminum) as the heterogeneous radiation in question. (See discussion of various methods of expressing X-ray qualities in a paper by L. S. Taylor, B. S. Jour. Research, vol. 5 (RP212), p. 517, 1930.)

"The "Rontgen" ( $r)$, is defined as the quantity of radiation which, when the secondary electrons are fully utilized and the wall effect of the chamber is avoided, produces in $1 \mathrm{~cm}^{3}$ of atmospheric air at $0^{\circ} \mathrm{C}$., and $76 \mathrm{~cm}$ mercury pressure such a degree of conductivity that one electrostatic unit charge is measured at saturation current.

"The "percentage depth dose" is the ratio of the X-ray intensity as measured at a given depth in a body of homogeneous material, to the intensity as measured at the irradiated surface. It must be recognized thaf these intensities are measured in terms of Röentgens per minute and hence do not give true indications of the energy absorbed in a given volume element.

"Up to the present the term "constant potential" has been used carelessly in describing the potential supplied by kenotron or other valve tube rectification. We will use a more accurate designation of voltages which are actually not constant but fluctuate about a certain average value. Thus by a "ripple quantity" (potential or current) is meant a simple periodic quantity

$$
y=V_{0}+V_{1} \sin \left(\omega x+\alpha_{1}\right)+V_{2} \sin \left(2 \omega x+\alpha_{2}\right)+\ldots
$$

in which the constant term $\left(V_{0}\right)$ is so large that all values of the quantity are positive (or negative). The amount of ripple ("ripplage" or "ripplance") in a ripple quantity is the ratio of the difference between
} the maximum and minimum values of the quantity to the average value. 
scale voltmeter connected directly across the transformer primary. Duplication of results over a period of months indicated that this control method was sufficient. In the case of the generator $C$ ("constant potential") the control was effected by means of a shielded high-tension voltmeter ${ }^{7}$ connected directly across the tube leads.

Peak voltage was measured with a sphere gap in all cases. Average voltages were measured by means of the high-tension voltmeter, which in the case of generator $C$ gave readings very slightly less than those of the sphere gap, depending upon the tube current. Since the rectification characteristics of generators $A$ and $B$ vary with load, this was kept constant at $4 \mathrm{ma}$ (average) throughout the entire work.

The rectifying switch of generator $B$ was fixed in a permanent position on the synchronous motor shaft, so measurements made with

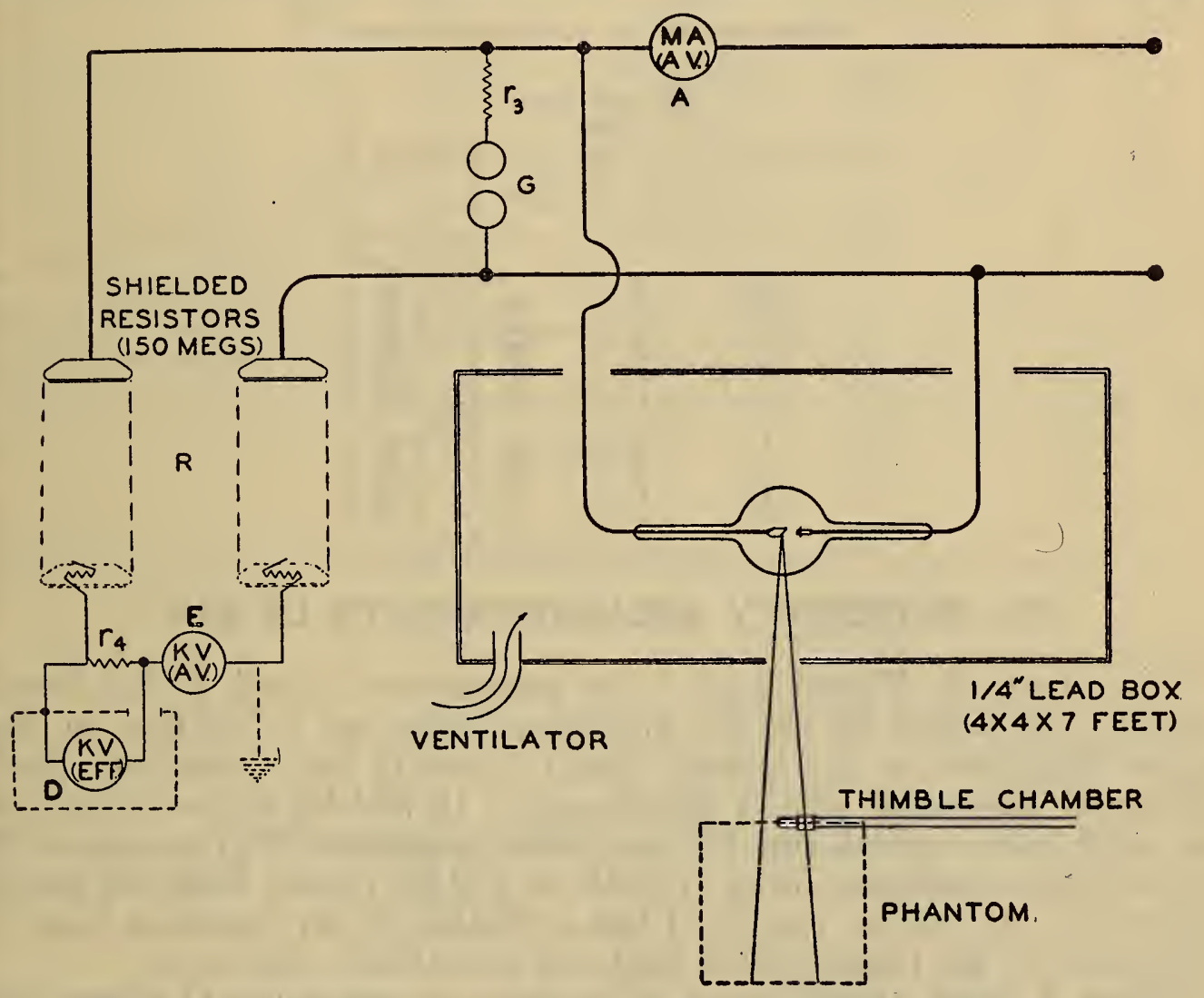

FIGURE 1.-Diagram of apparatus showing current and voltage measuring systems

$B$ were arbitrarily chosen as a basis in comparing with $A$. The switch on $A$ was so arranged that its phase position could be readily changed. The positions of the switches were at the points set by the agents of the respective manufacturers - presumably best suited for use at $200 \mathrm{kv}$ (peak).

Ionization measurements were made with a calibrated thimble ionization chamber arranged according to the diagram in Figure 1. The distance from focal spot to center of the chamber was $104 \mathrm{~cm}$. The ionization chamber system was tested for leakage by covering the thimble chamber cap with lead and then exposing it to the X-ray beam. No leakage was detectable in an exposure time double the longest used in the measurements. 
For depth dose measurements a cubical wax phantom about $35 \mathrm{~cm}$ on a side was used. Wax was selected instead of water largely for convenience since its difference from water has been shown ${ }^{8}$ to be insignificant. The wax was carved out so that the chamber in the surface position was half submerged leaving no air pockets between it and the wax. The focal spot-surface distance was likewise $104 \mathrm{~cm}$. A beam area of $10 \mathrm{~cm}$ diameter $\left(78 \mathrm{~cm}^{2}\right)$ at the position of the chamber was chosen in order to work with a clearly defined field receiving little stem radiation. Table 1 from Grebe and Nitzge shows that within wide limits variations of depth dose with quality are independent of the field area.

TAsLe 1.-Relationship between radiation quality and percentage depth dose for two different field areas

$A$, field area $400 \mathrm{~cm}^{2} ; B$, field area $50 \mathrm{~cm}^{2}$

\begin{tabular}{|c|c|c|c|}
\hline \multirow{2}{*}{ H. V. L. } & \multicolumn{2}{|c|}{$\begin{array}{l}\text { Per cent depth } \\
\text { dose }\end{array}$} & \multirow{2}{*}{ Ratio } \\
\hline & $A$ & $B$ & \\
\hline $\begin{array}{c}m m C u \\
2.00 \\
1.6 \\
1.0 \\
.8 \\
.6\end{array}$ & $\begin{array}{l}52 \\
51 \\
50 \\
48 \\
47\end{array}$ & $\begin{array}{l}30 \\
30 \\
29 \\
28 \\
27\end{array}$ & $\begin{array}{l}A / B \\
1.73 \\
1.70 \\
1.72 \\
1.72 \\
1.74\end{array}$ \\
\hline $\begin{array}{l}.4 \\
.2 \\
.1 \\
.05\end{array}$ & $\begin{array}{r}40 \\
28 \\
16 \\
7\end{array}$ & $\begin{array}{r}24 \\
16 \\
9 \\
4\end{array}$ & $\begin{array}{l}1.67 \\
1.75 \\
1.78 \\
1.75\end{array}$ \\
\hline
\end{tabular}

\section{INTENSITY MEASUREMENTS IN AIR}

The curves in Figure 2 give for generators $A$ and $B$ the beam intensity measured in air (in arbitrary units) as a function of the copper filtration in the beam. Each curve is for a constant peak voltage as measured with a sphere gap. It will be noticed that, for the same tube current and $200 \mathrm{kv}$ (peak) generator $B$ gives about 20 per cent more radiation than $A$ while at $180 \mathrm{kv}$ (peak) both are about the same. At $160 \mathrm{kv}$ (peak) $A$ has a greater $\mathrm{X}$-ray emission than $B$ and from $140 \mathrm{kv}$ (peak) down both are essentially the same.

Figure 3 gives a similar set of curves for generator $C$ where the voltages are expressed in kilovolts average. The curve for $150 \mathrm{kv}$ (average), replotted as the broken line on Figure 2, approximates very closely the curve for $200 \mathrm{kv}$ (peak) on generator $B$. Similarly, it will be found for the conditions used here that the other approximate intensity equivalents given in Table 2 are obtainable for radiation filtered through $0.5 \mathrm{~mm}$ of copper.

Thus to obtain an X-ray intensity of 178 units from any of the three generators, through $0.5 \mathrm{~mm}$ copper filter, would require that $A$ be operated at $200 \mathrm{kv}$ (peak), $B$ at $189 \mathrm{kv}$ (peak), and $C$ at $142 \mathrm{kv}$ (average). This is, of course, for the same tube current in all cases. Similarly, an intensity of 80 units is obtained at $138 \mathrm{kv}$ (peak), 140 $\mathrm{kv}$ (peak), and $99 \mathrm{kv}$ (average), respectively.

\footnotetext{
${ }^{8}$ Grebe and Nitzge, Strahlen (Sonderbände), vol. 14, 1930.
} 

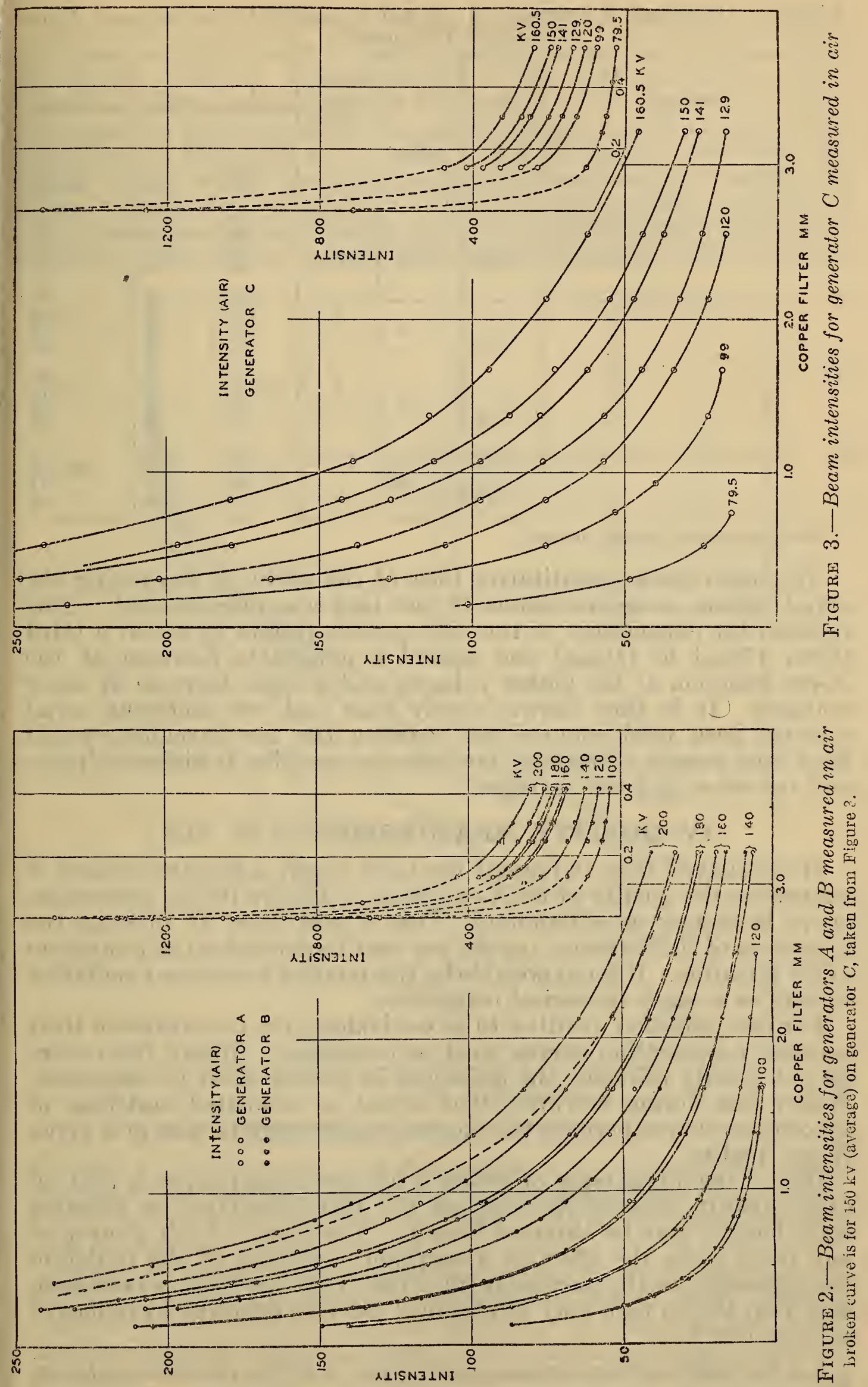
TABLE 2.-Potentials of generators $A, B$, and $C$ required to produce equal $X$-ray intensities or qualities

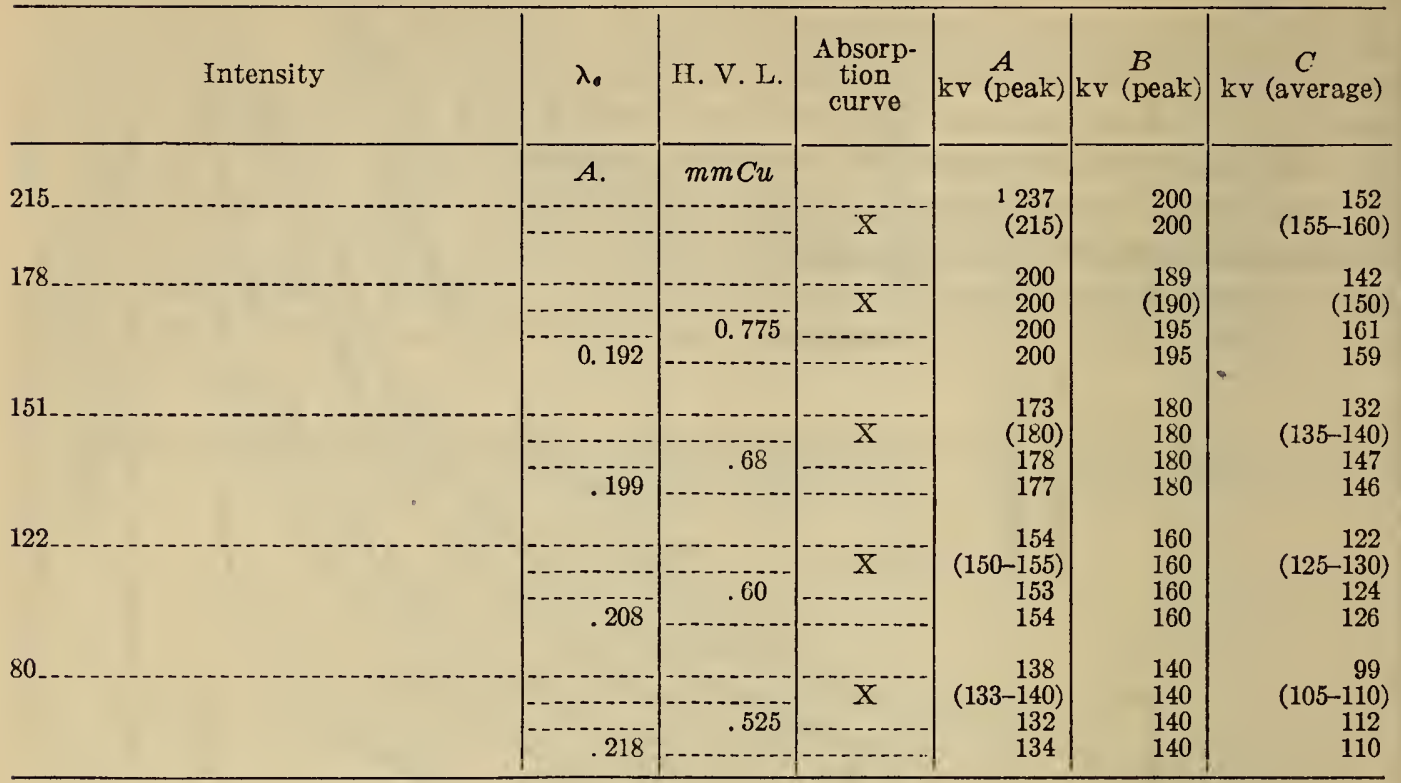

1 Extrapolated value, probably too high.

To obtain some quantitative idea of the effect of shortening the aerial system, a section about 12 feet long was disconnected. This reduced the capacitance of the high-tension system by about a third (from $158 \mu \mu \mathrm{f}$ to $110 \mu \mu \mathrm{f}$ ) and caused a noticeable decrease of the X-ray emission at the higher voltages and a slight increase at lower voltages. It is thus shown clearly that had two different aerial systems been used comparisons between the two machines would have been grossly misleading, favoring one machine at higher voltages and the other at lower voltages.

\section{QUALITY MEASUREMENTS IN AIR}

It is believed that at present the most nearly adequate method of expressing the quality of an X-ray beam is to give its full absorption curve in copper or aluminum. ${ }^{9}$ This is best done by plotting the logarithm of the intensity (or the per cent transmission) as a function of the filtration. It is not possible by this method to express a radiation quality as a single numerical magnitude.

For two radiation qualities to be equivalent, the curvatures of their respective absorption curves must be coincident. Where two curves do not exactly coincide, the difference in quality must be estimated. Wilsey has shown, however, that actual or estimated matching of absorption curves permits the most accurate reproduction of a given X-ray quality.

One of the advantages of giving a full absorption curve is that all other quality expressions, such as the half-value-layer or effective wave length, may be obtained from it. The slope of such a curve at any point gives the effective absorption coefficient of the radiation corresponding to the particular filter for which the point was chosen, and from this in turn may be obtained the true effective wave length of the beam. ${ }^{10}$

\footnotetext{
9 E. A. Pohle, and C. S. Wright, Radiology, vol 14, p. 17, 1930. R. B. Wilsey, Radiology, vol. 17, p. 700, 1931.

${ }_{10}$ L. S. Taylor, B. S. Jour. Research, vol. 5, p. 517, 1930. This corresponds to Mutscheller's “average wave length."
} 
Figures 4, 5, and 6 give the copper absorption curves for generators $A, B$, and $C$ respectively. These curves are from the same data used for Figures 2 and 3 . It is significant to note that the $200 \mathrm{kv}$ (peak) curve for generator $B$ indicates a generally more penetrating radiation than for generator $A$ at the same voltage. At $180 \mathrm{kv}$ (peak) the qualities are about the same, while at $150 \mathrm{kv}$ (peak) the reverse obtains. From $140 \mathrm{kv}$ (peak) down, the qualities are again roughly the same. In other words, as shown in Table 2 , the qualities of the radiations bear a similar relationship to one another as do the intensities so that, for a given peak voltage, and a given filtration, if the radiation

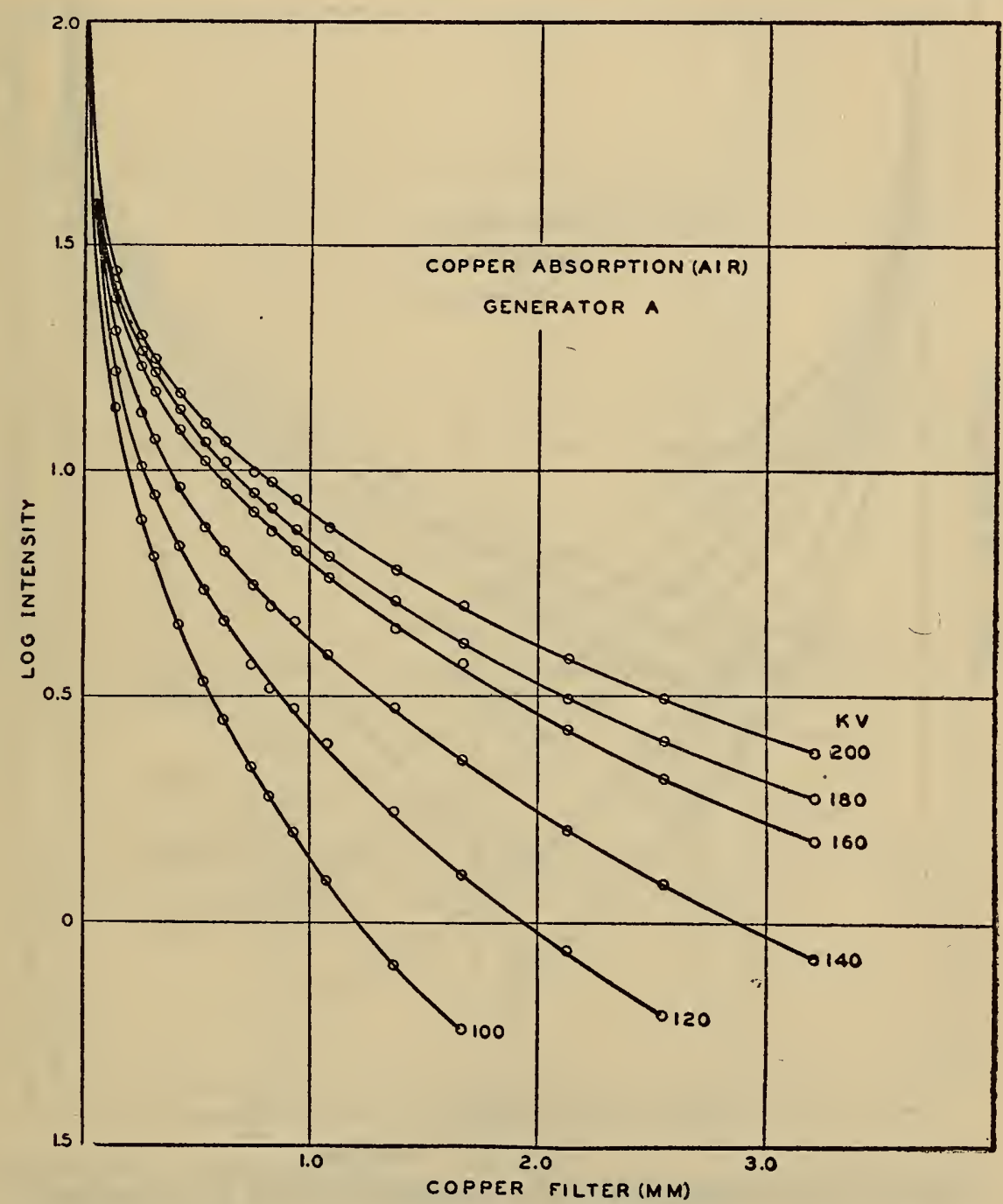

Figure 4.-Semilogarithmic copper absorption curve for generator $A$

emission of $A$ is greater than $B$ the penetration of $A$ is likewise greater than $B$. It is unsafe to draw any generalization from these results, but it may be noted that such is roughly the case for all conditions thus far encountered in this work.

In Figure 6, giving the copper absorption curves for generator $C$, the broken lines are transposed from Figures 4 and 5 . It will be noted that the $200-\mathrm{kv}$ (peak) curve for generator $B$ (upper broken curve) corresponds very nearly in slope to the $150-\mathrm{kv}$. (average) curve for generator $C$. (It will be recalled that the corresponding intensity curves also nearly coincide.) Similarly, it is found possible to match 
the other absorption curves for the different generators and we find that Table 2 above for intensity equivalents holds approximately true for quality equivalents, also.

\section{DEPTH DOSE MEASUREMENTS}

Measurements of the percentage depth dose were made over the whole range of radiation qualities used. Figures 7,8 , and 9 give, respectively, the surface and 10-cm depth intensities for generators $A, B$, and $C$. Comparison of the curves for the two mechanical rec-

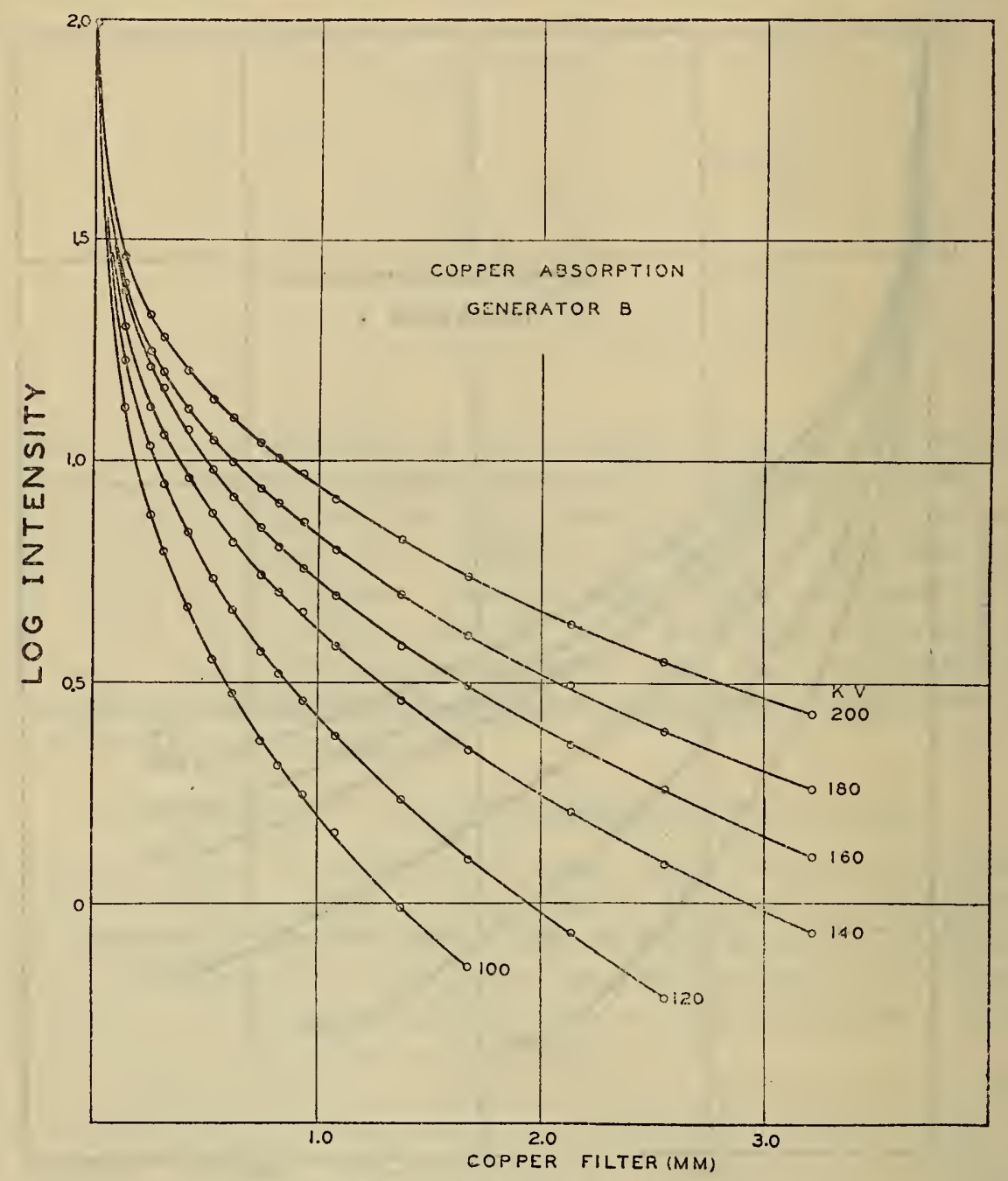

FigURE 5.-Semilogarithmic copper absorption curve for generator $B$

tifiers shows the same general similarities as were evidenced by the air intensity curves given in Figures 2 and 3 . Thus the $200-\mathrm{kv}$ curve for generator $B$ (broken line curve in fig. 7 ) shows a considerably greater surface dose than the 200-kv curve for generator $A$.

Again the intensities measured at $10 \mathrm{~cm}$ depth for the two machines are related in the same manner as the air intensities.

The broken line curves in Figure 8 are intensities for generator $B$ when used with the shortened aerial system. As noted for the air intensity measurements, the long aerial system has a greater X-ray emission at 200 and $180 \mathrm{kv}$ and a smaller emission at $160 \mathrm{kv}$ than the short aerial system. Below $160 \mathrm{kv}$ there appears to be no significant difference between generators. 
In comparing generator $C$ with $A$ and $B$, it is found (fig. 9) that $160.5 \mathrm{kv}$ (average) on $C$ produces slightly greater air and surface intensities than $200 \mathrm{kv}$ (peak) on generator $B$ while $150 \mathrm{kv}$ (average) on $C$ is about equivalent to $200 \mathrm{kv}$ (peak) on generator $A$. Also $140 \mathrm{kv}$ (average) on $C$ is seen to be equivalent to $180 \mathrm{kv}$ (peak) on either $A$ or $B$.

Quality measurements as here carried out, with the thimble chamber at the phantom surface and at $10 \mathrm{~cm}$ depth, have no real

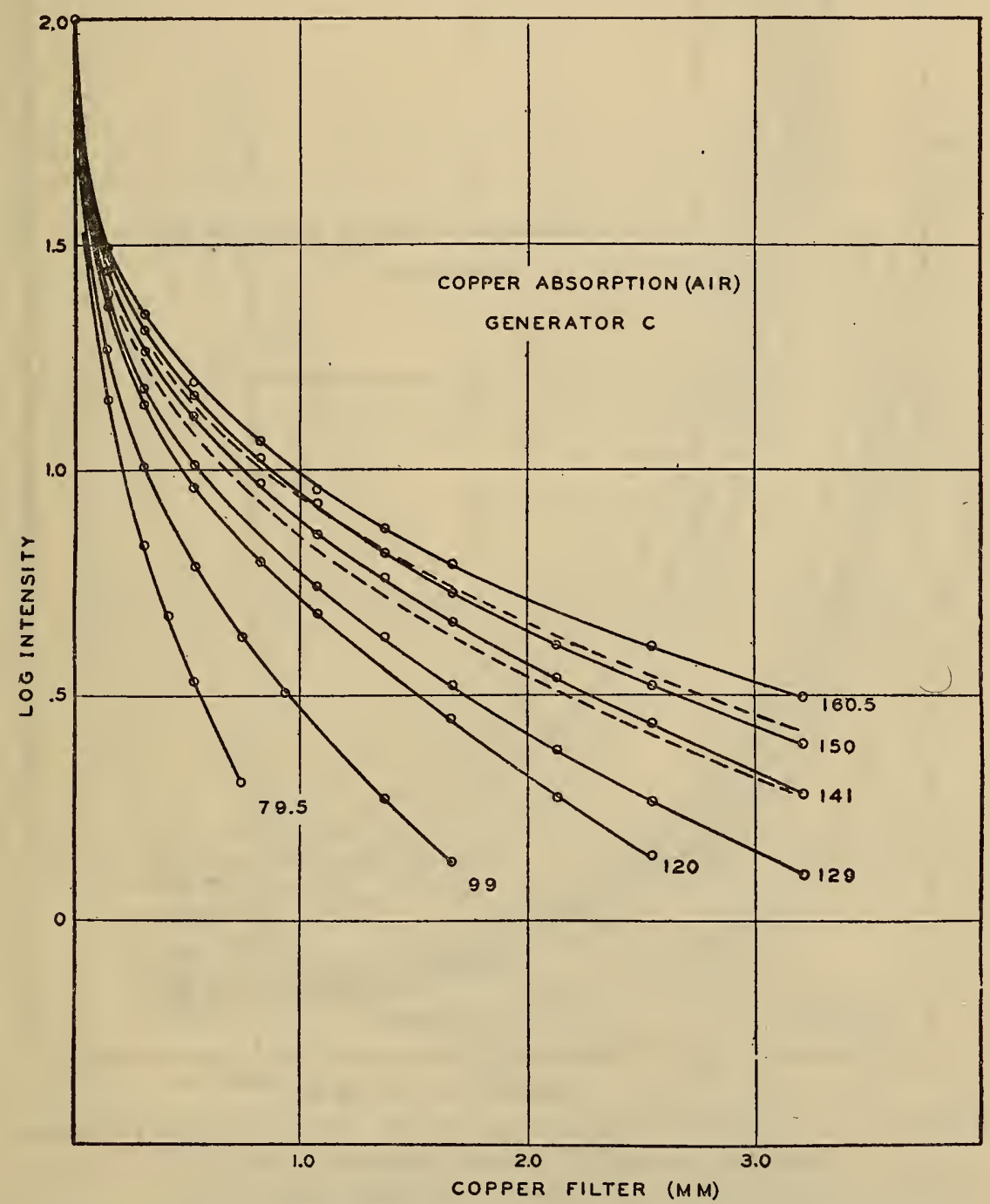

FIGURE 6.-Semilogarithmic copper absorption curve for generator $C$ Upper broken line curve for generator $B$ at $200 \mathrm{kv}$. Lower broken line curve for generator $A$ at $180 \mathrm{kv}$.

significance in relating the radiation quality in a phantom to that in air. This is because radiation under such conditions contains a major proportion of very soft scattered X rays that introduce a large and unknown wall correction into the measurements. Since it is impossible to reproduce such radiations entering a standard chamber, the thimble chamber can not be calibrated for equivalent radiation qualities.

Such curves have significance, however, in comparing radiation qualities measured under identical experimental conditions, and as such have been used to compare depth dose qualities. 
Figures 10, 11, and 12 give the copper absorption (corresponding to the intensity curves of figs. 7,8 , and 9) measured at the surface and $10 \mathrm{~cm}$ depth for generators $A, B$, and $C$, respectively. On the assumption that similar absorption curves, obtained under identical conditions, imply equivalent radiations, these curves show precisely the same relation between the $10 \mathrm{~cm}$ depth radiation qualities for the

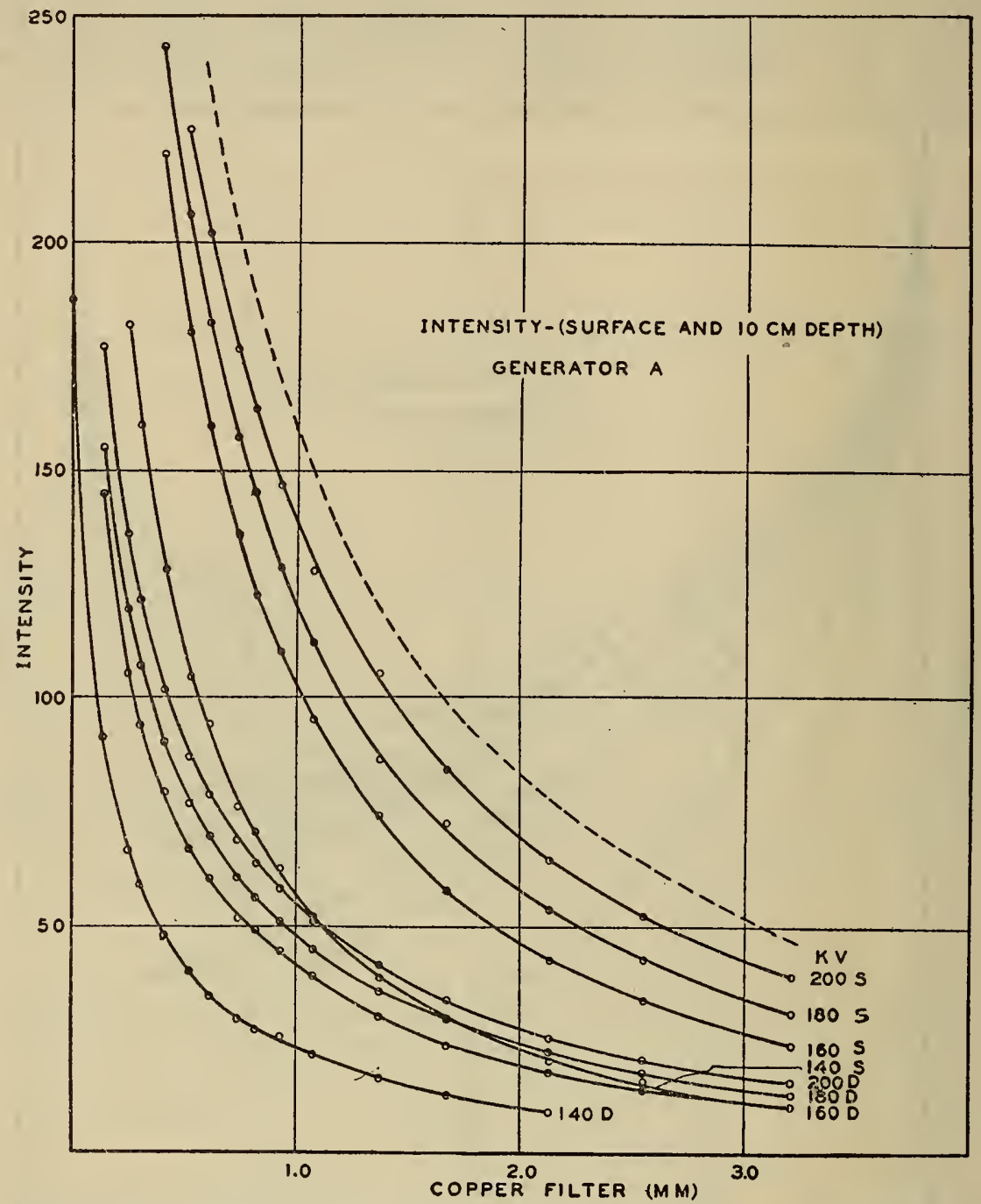

FIgURE 7.-Beam intensities for generator $A$ measured at phantom surface $(S)$ and at $10 \mathrm{~cm}$ phantom depth $(D)$

Broken curve is for $200 \mathrm{kv}$ on generator $B$ measured at surface.

three generators as was indicated by the absorption curves measured in air.

Percentage depth doses for all the conditions here used may be obtained directly from the curves in Figures 7, 8, and 9. It happens that the percentage depth dose changes but very slowly with increasing hardness of radiation after one or two tenths of a millimeter copper filtration. It also changes but slightly with increase of voltage above $160 \mathrm{kv}$ (peak). Consequently, the change in percentage depth dose is an insensitive indicator of radiation equalities. It can not, however, be neglected; since, if two radiations, having otherwise similar properties, should differ materially in percentage depth dose, there would be no justification for saying that they were equivalent. ${ }^{11}$

11 It should be noted that a percentage depth dose is the ratio between two measurements and hence its error may be considerably larger than the individual errors of the original measurements. 
The change of depth dose with filtration for the three generators is given in Table 3. It is seen that, while the accuracy is none too good, the percentage depth dose with generators $A$ and $B$ are about the same at equal voltages. The depth doses at $160 \mathrm{kv}$ appear to be slightly greater than at higher voltages which is probably unreasonable but may be due to small cumulative errors. In comparing generator $C$ with the mechanical rectifiers, it is found that the depth doses at 160

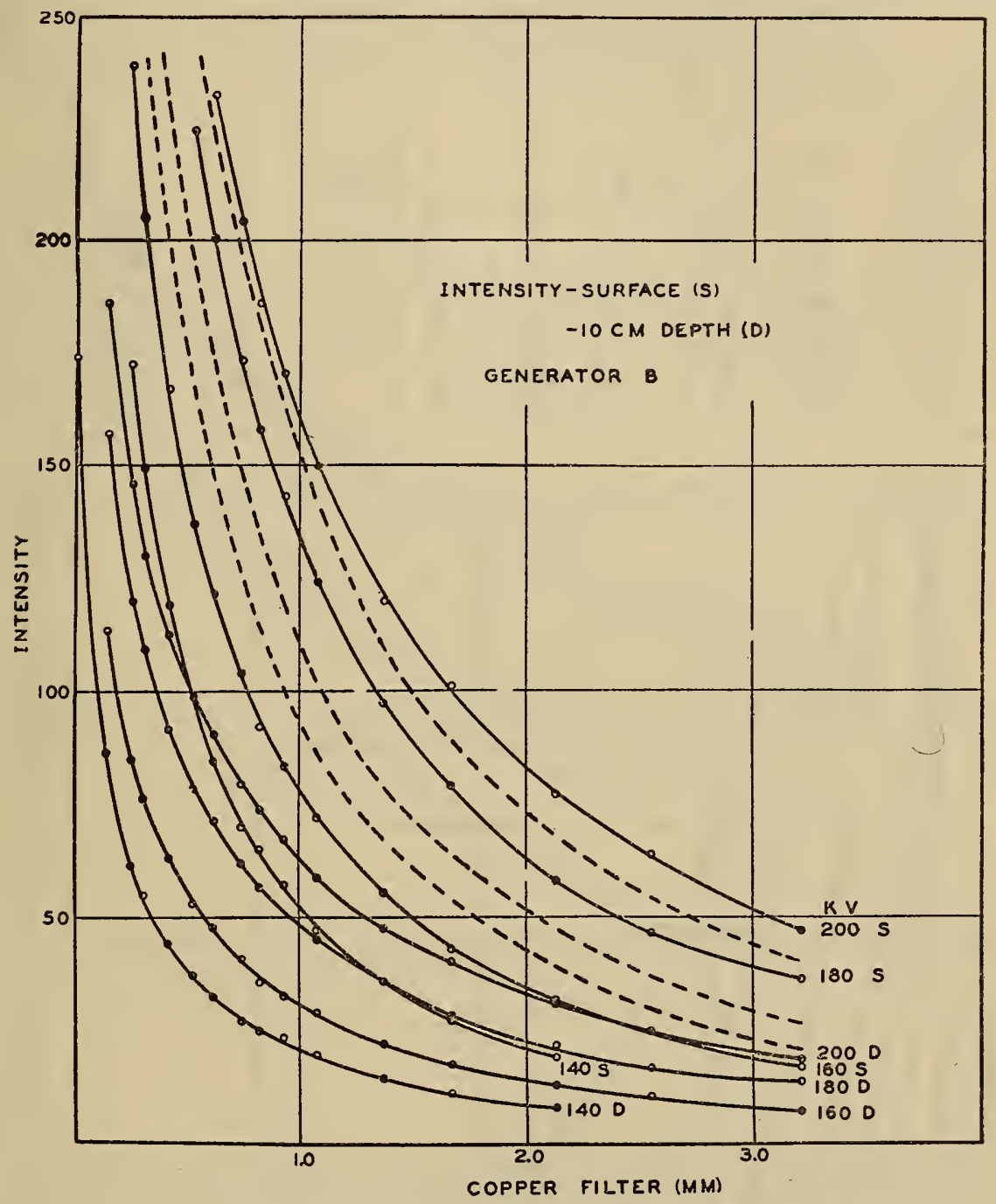

FIGURE 8.-Beam intensities for generator $B$ measured at phantom surface $(S)$ and at $10 \mathrm{~cm}$ phantom depth $(D)$

Broken line curves (top to bottom) for surface intensities for same generator except with shortened aerial operating at 200,180 , and $160 \mathrm{kv}$ (peak).

$\mathrm{kv}$ (average) for $C$ slightly exceed those at $200 \mathrm{kv}$ (peak) for $A$ and $B$ and likewise the depth doses at $140 \mathrm{kv}$ (average) for $C$ are slightly greater than those at $180 \mathrm{kv}$ (peak) for $A$ and $B$. At $160 \mathrm{kv}$ (peak) generators $A$ and $B$ give a slightly greater depth dose than $C$ operating at $120 \mathrm{kv}$ (average). The importance of these depth-dose measurements rests in their agreement and no inference should be drawn from the small differences found. 
TABLE 3.-Percentage depth doses in wax phantom (field $10 \mathrm{~cm}$ diameter) for different copper filtrations

\begin{tabular}{|c|c|c|c|c|c|c|c|c|c|}
\hline \multirow{4}{*}{ Filter } & \multicolumn{2}{|c|}{$\mathrm{kV}$ (peak) } & \multirow{2}{*}{$\frac{\begin{array}{c}\text { kv (av- } \\
\text { erage) }\end{array}}{160.5}$} & \multicolumn{2}{|c|}{$\mathrm{kv}$ (peak) } & \multirow{2}{*}{\begin{tabular}{|c|}
$\begin{array}{c}\mathrm{kv} \text { (av- } \\
\text { erage) }\end{array}$ \\
140
\end{tabular}} & \multicolumn{2}{|c|}{$\mathrm{kv}$ (peak) } & \multirow{2}{*}{\begin{tabular}{|c|}
$\begin{array}{c}\mathrm{kV} \text { (av- } \\
\text { erage) }\end{array}$ \\
120
\end{tabular}} \\
\hline & 200 & 200 & & 180 & 180 & & 160 & 160 & \\
\hline & \multicolumn{9}{|c|}{ Machine } \\
\hline & $A$ & $B$ & $C$ & $A$ & $B$ & $C$ & $A$ & $B$ & $C$ \\
\hline$\underset{0}{m m} C u$ & 18 & 18 & & 17 & 16 & & 16 & & \\
\hline $\begin{array}{l}0.14 \\
0.304\end{array}$ & 35 & 34 & 34.8 & 34 & 31 & 34.2 & 34 & 33 & 29.3 \\
\hline 0.415 & 37 & 38 & & 37 & 35 & & 37 & 38 & \\
\hline $\begin{array}{l}0.6 \\
0.8\end{array}$ & $\begin{array}{l}38 \\
38\end{array}$ & $\begin{array}{l}38 \\
39\end{array}$ & 38.3 & $\begin{array}{l}37 \\
38\end{array}$ & $\begin{array}{l}37 \\
37\end{array}$ & 38.4 & $\begin{array}{l}37 \\
39\end{array}$ & $\begin{array}{l}39 \\
39\end{array}$ & 37.7 \\
\hline 1.0 & 38 & 39 & 40.0 & 38 & 37 & 38.9 & 40 & 39 & \\
\hline 1.5 & 39 & 40 & & 39 & 38 & & 40 & 40 & 38.7 \\
\hline $\begin{array}{l}2.0 \\
2.5\end{array}$ & $\begin{array}{l}39 \\
38\end{array}$ & $\begin{array}{l}40 \\
39\end{array}$ & 41.3 & $\begin{array}{l}40 \\
38\end{array}$ & $\begin{array}{l}38 \\
37\end{array}$ & 40.4 & $\begin{array}{l}40 \\
40\end{array}$ & $\begin{array}{l}39 \\
40\end{array}$ & $-n-1$ \\
\hline 3. 0 & 39 & 39 & & 40 & 38 & & & & 40.0 \\
\hline
\end{tabular}

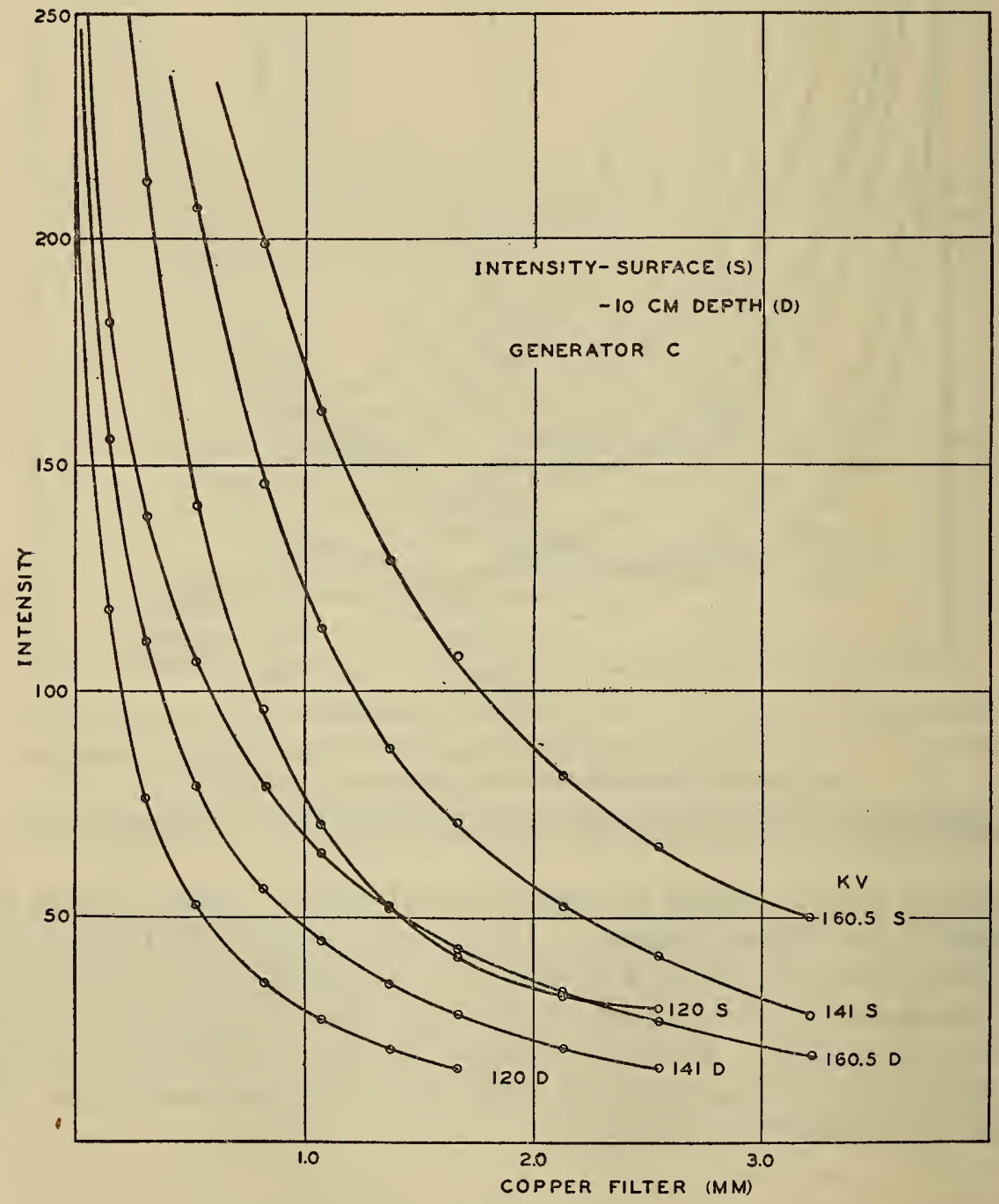

Figure 9.-Beam intensity for generator $C$ measured at phantom surface $(S)$ and at $10 \mathrm{~cm}$ phantom depth $(D)$ 


\section{HALF-VALUE LAYERS AND TRUE EFFECTIVE WAVE LENGTHS}

The results above have shown that the copper absorption curves for the three generators give a fairly reasonable comparison of the resulting tube emission as regards quantity, quality, and depth dose. From the curves given, effective wave lengths or half-value layers in copper for any desired beam of radiation may be obtained directly. In practice, radiation qualities have been variously expressed by either

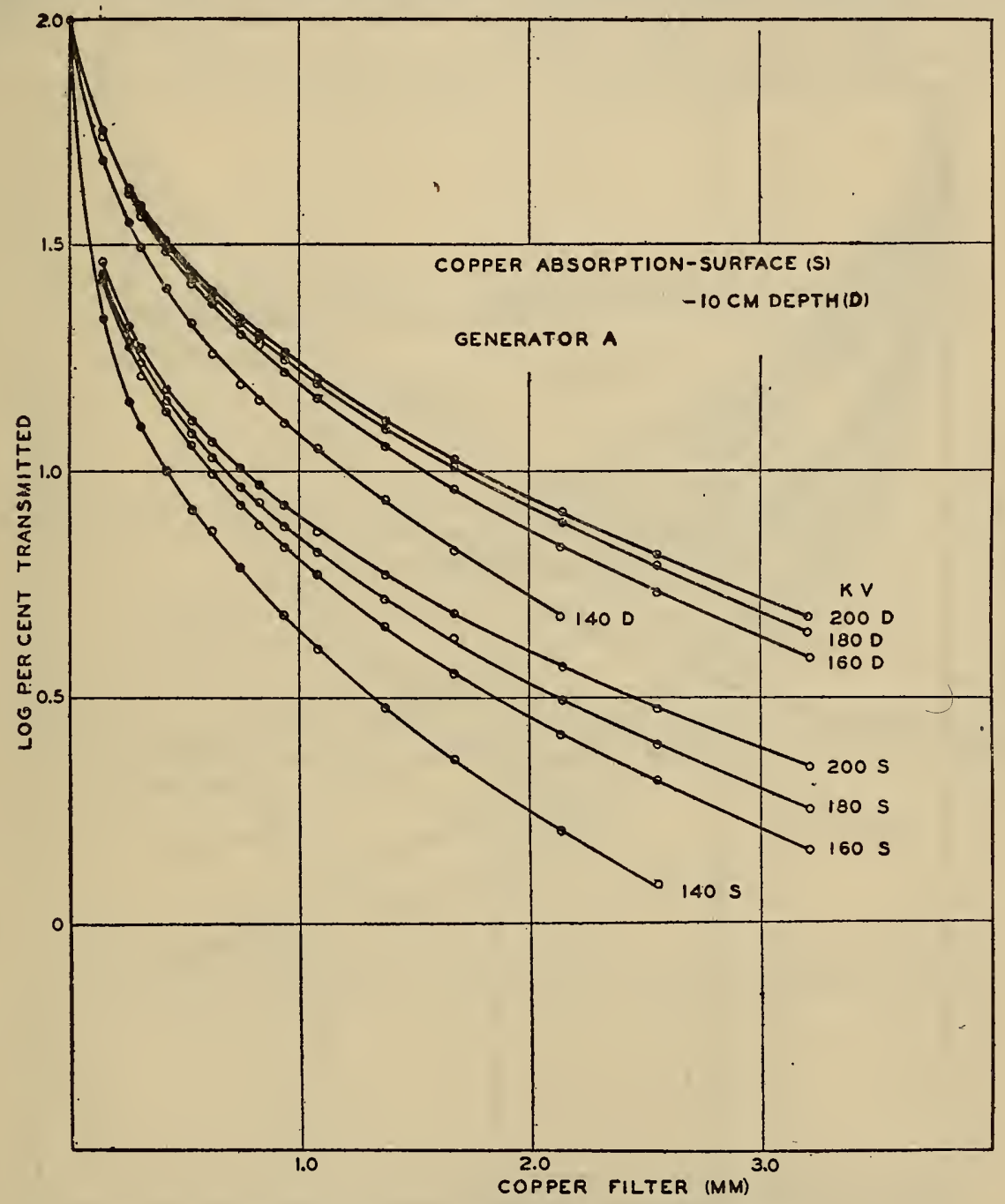

FIGURE 10.-Semilogarithmic copper absorption curves for radiation measured at surface $(S)$ and $10 \mathrm{~cm}$ depth $(D)$ on phantom for generator $A$

of these two methods. Hence, for facilitating comparisons of the radiation output of generators, values of the copper half-value layer (H. V. L.) and true effective wave length $\left(\lambda_{e}\right)$, covering all the radiations used in this study, have been plotted in Figures 13 and 14 . It should be emphasized that the values for mechanical rectifiers are likely to vary somewhat between machines and that the values here given hold strictly only for our generators. They should, however, serve as a fairly close guide.

Values of H. V. L. and $\lambda_{e}$ also depend upon the thickness of the tube wall, this probably accounting for the differences in H. V. L. for "constant potential" reported by several workers. Probably a more 
serious source of difference between workers lies in their method of voltage measurement and in the amount of ripplage present in their generator. When using generator $C$ the ripplage was found to be about 8 per cent and to vary slightly with voltage. Voltage measurements were made by means of a shielded high resistance "voltmeter multiplier" in series with a d. c. microammeter. ${ }^{12}$ Thus the potentials are expressed in average kilovolts whereas the potentials used by other workers in measuring $H$. V. L. were usually, if not always, in peak kilovolts. To show how various observers agree, their results are plotted in Figure 15. There appears to be no systematic difference

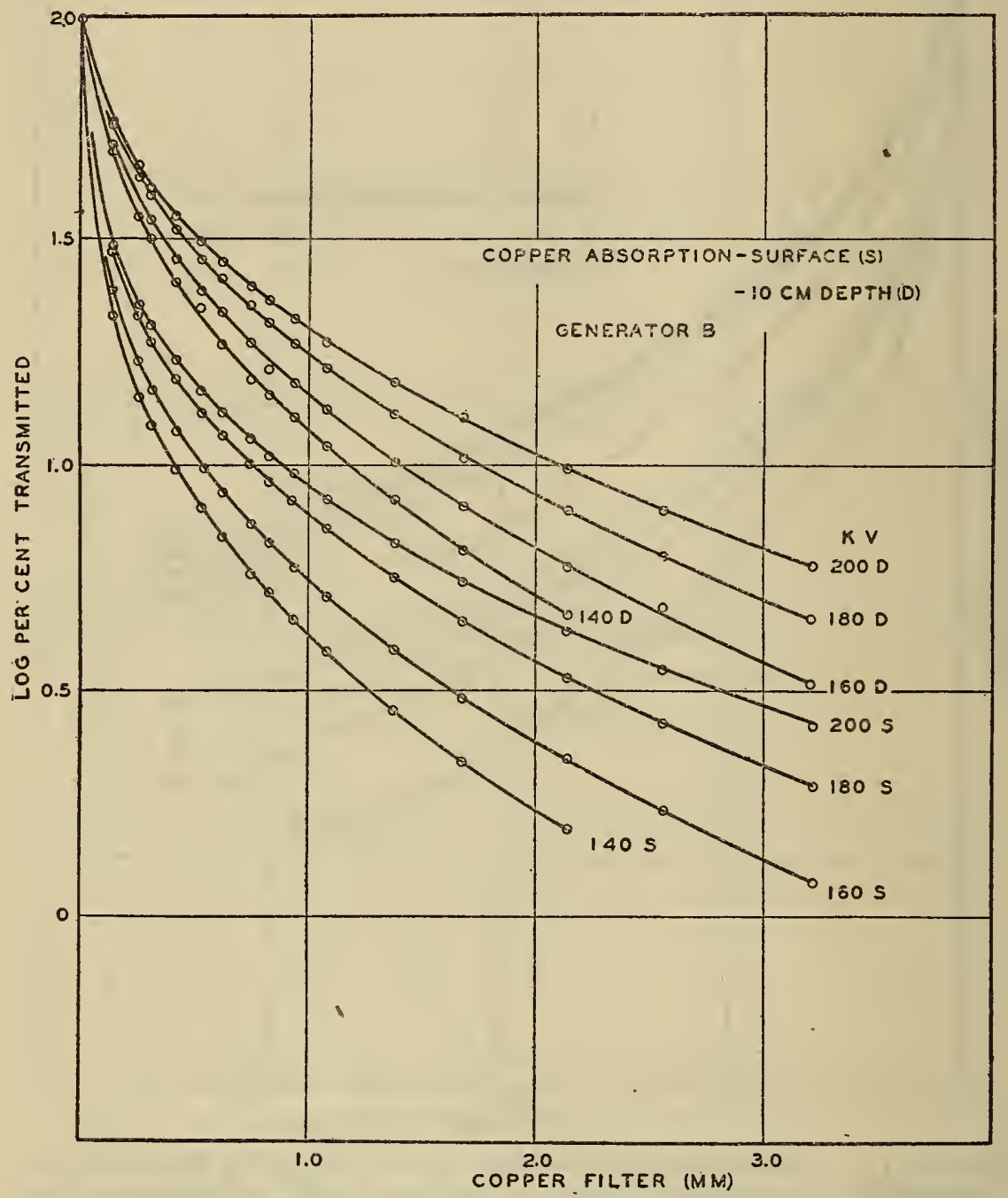

FigURE 11.-Semilogarithmic copper absorption curves for radiation measured at surface $(S)$ and $10 \mathrm{~cm}$ depth $(D)$ on phantom for generator $B$

except that Holthusen's are consistently higher than all others. Our measurements fall between the others over a large portion of the range covered.

The "quality" comparisons of the three generators, made from the full absorption curves, are borne out very well by the H. V. L. and $\lambda_{e}$ curves of Figures 13 and 14. For example, an X-ray beam, filtered with $0.5 \mathrm{~mm}$ copper and having an $\mathrm{H}$. V. L. of $0.75 \mathrm{~mm} \mathrm{Cu}$, may be obtained with $200 \mathrm{kv}$ on generator $A, 195 \mathrm{kv}$ on $B$, and $160 \mathrm{kv}$ on $C$. 
Again a beam filtered with $0.25 \mathrm{~mm}$ copper and having an $\mathrm{H}$. V. L. of $0.50 \mathrm{~mm}$ copper may be obtained with $210 \mathrm{kv}$ on $A, 202 \mathrm{kv}$ on $B$, and $150 \mathrm{kv}$ on $C$. We find a similar relationship from the effective wavelength curves. Thus a beam filtered with $0.5 \mathrm{Cu}$ and having a value of $\lambda_{e}=0.195$ Angstrom may be obtained with $200 \mathrm{kv}$ on $A, 196 \mathrm{kv}$ on $B$, and $160 \mathrm{kv}$ on $C$. Again a $0.25 \mathrm{~mm}$ copper filtered beam having $\lambda_{e}=0.235$ Angstrom is obtained by $212 \mathrm{kv}$ on $A, 203 \mathrm{kv}$ on $B$, and $150 \mathrm{kv}$ on $C$. The agreement of these with the results obtained from the H. V. L. curves is probably within the experimental error.

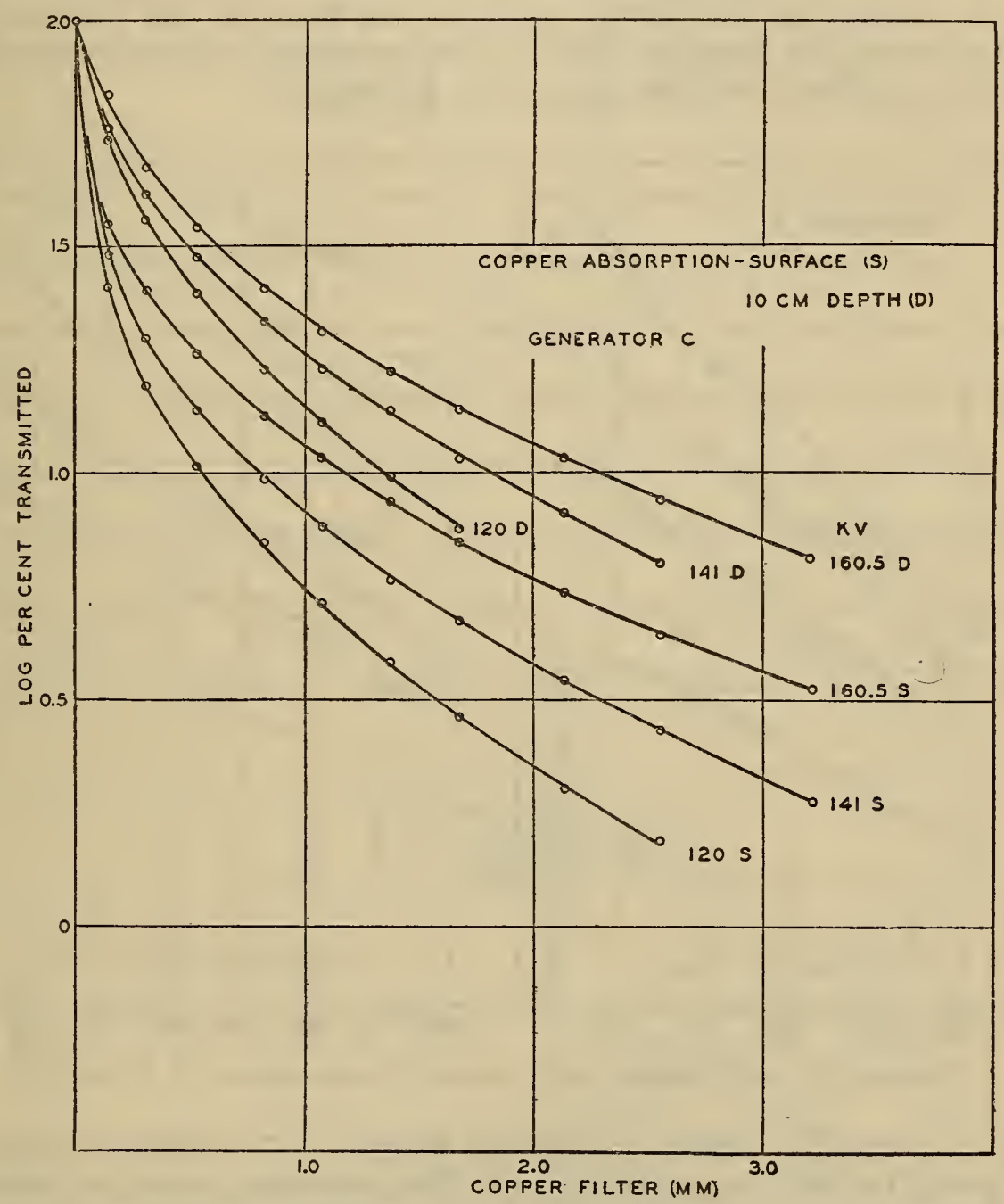

FIgURE 12.-Semilogarithmic copper absorption curves for radiation measured at surface $(S)$ and $10 \mathrm{~cm}$ depth $(D)$ on phantom for generator $C$

\section{VOLTAGE IMEASUREMENTS}

A partial explanation, at least, for the variation in X-ray emission under apparently identical conditions, is found to lie in the method of voltage measurement. The emission of an X-ray tube operating on a mechanically rectified generator depends upon the wave form of the voltage and the voltage-space current characteristic of the tube. If the tube current saturation is reached at a comparatively low voltage, then the voltage wave form of the generator is the predominant factor in determining the tube output. The wave form in turn depends upon current load drawn from the generator, the voltage, and the 
setting of the rectifying switches. It happens that, in general, no single setting of the rectifiers will suffice to yield the maximum output for all current and voltage combinations. In practice a single rectifier setting is used for all operating conditions and as a consequence the optimum output is realized only for a narrow range of conditions.

In measuring the voltage with a sphere gap the peak of the wave is the quantity determined, regardless of the wave form. Thus while the peak voltage of two waves may be the same, if one is a sharptopped wave form while the other is broad-topped, it is obvious that the tube output for the latter will exceed that of the former. This condition may be largely met if the generator output voltage be measured in effective rather than peak kilovolts.

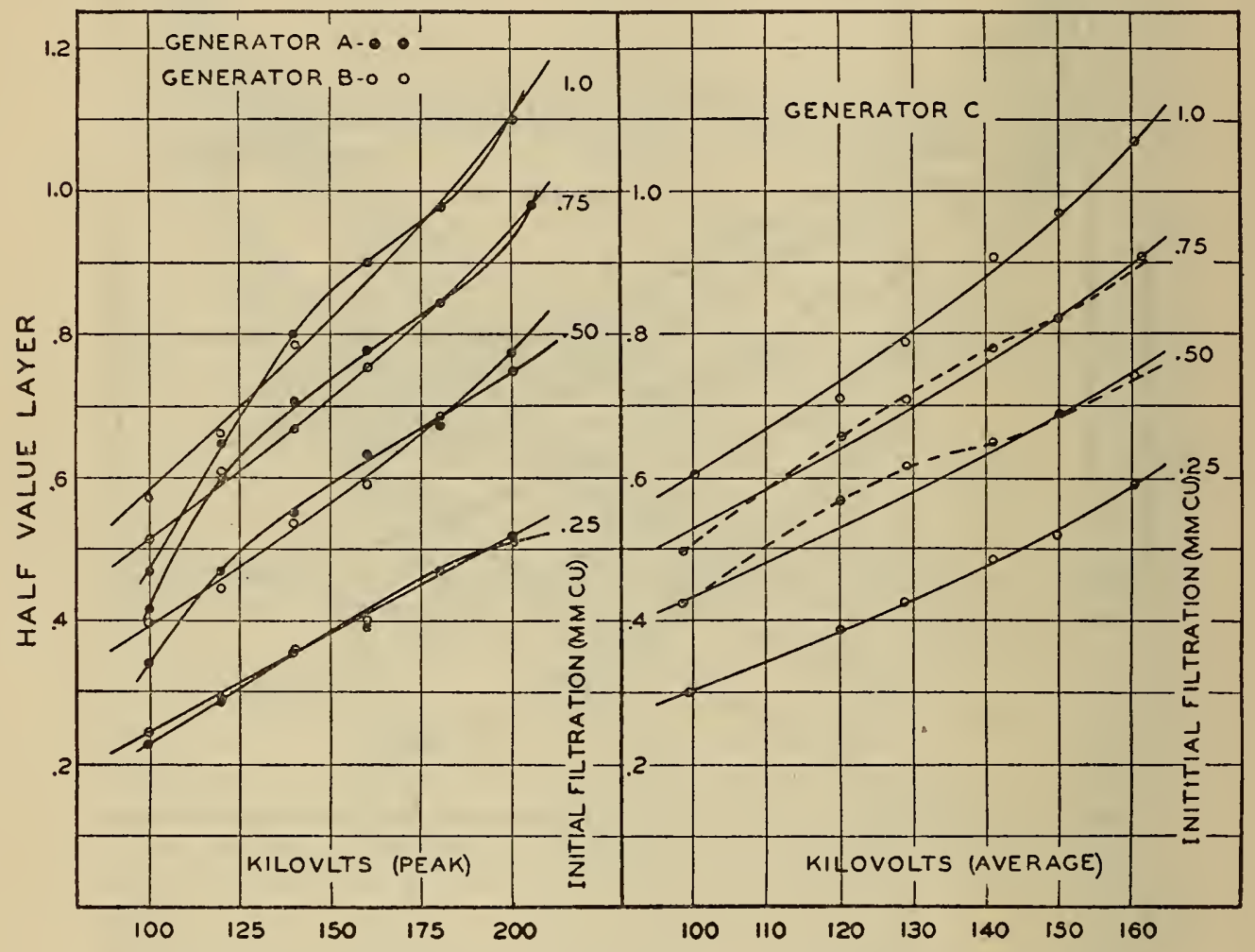

Figure 13.-Half-value layer curves for generators $A, B$, and $C$

This was readily accomplished by means of the high voltage voltmeter described in conjunction with the constant potential generator. As used up to the present, the 150 megohm noninaluctive shielded resistor ${ }^{13}$ was in series with a d. c. microammeter and thus measured average voltage. When the $\mathrm{d}$. c. instrument is replaced by an a. c. microammeter the potential is measured in effective kilovolts. In this work, the latter instrument not being readily available, we used a Kelvin multicellular electrostatic voltmeter to measure the potential drop across $75,000 \mathrm{ohms}$ placed in series with the main high resistance. The meter then read the voltage across the line.

In the case of generator $C$ the effective and average voltages are nearly identical. However, for mechanically rectified potentials,

\footnotetext{
${ }_{13}$ These have been described in paper referred to in footnote 7, p. 335 . It was found that the separate
} units making up the final resistor had a very slight negative reactance at 1,000 cycles. 


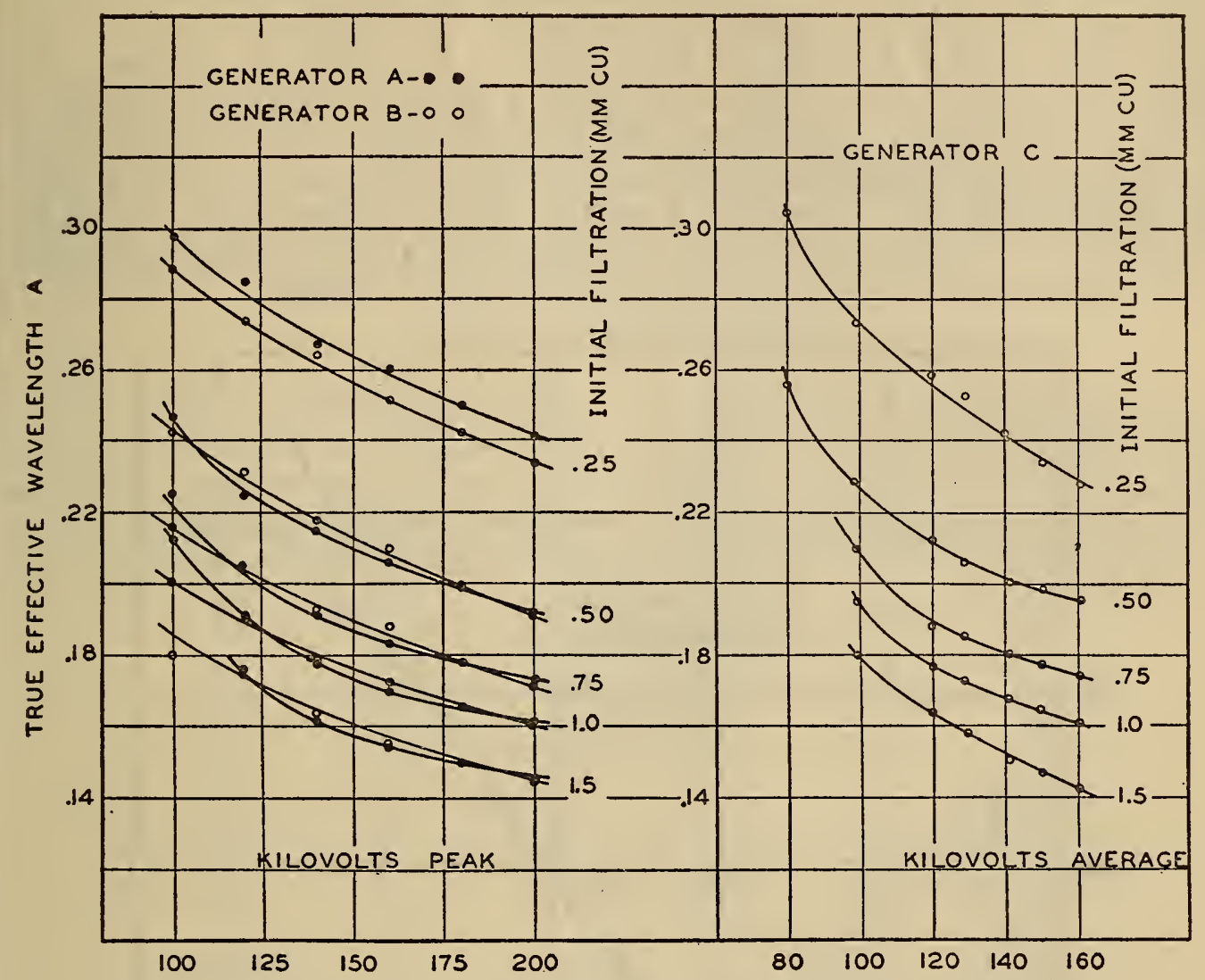

FIgURE 14.-Effective wave length curves for generators $A, B$, and $C$

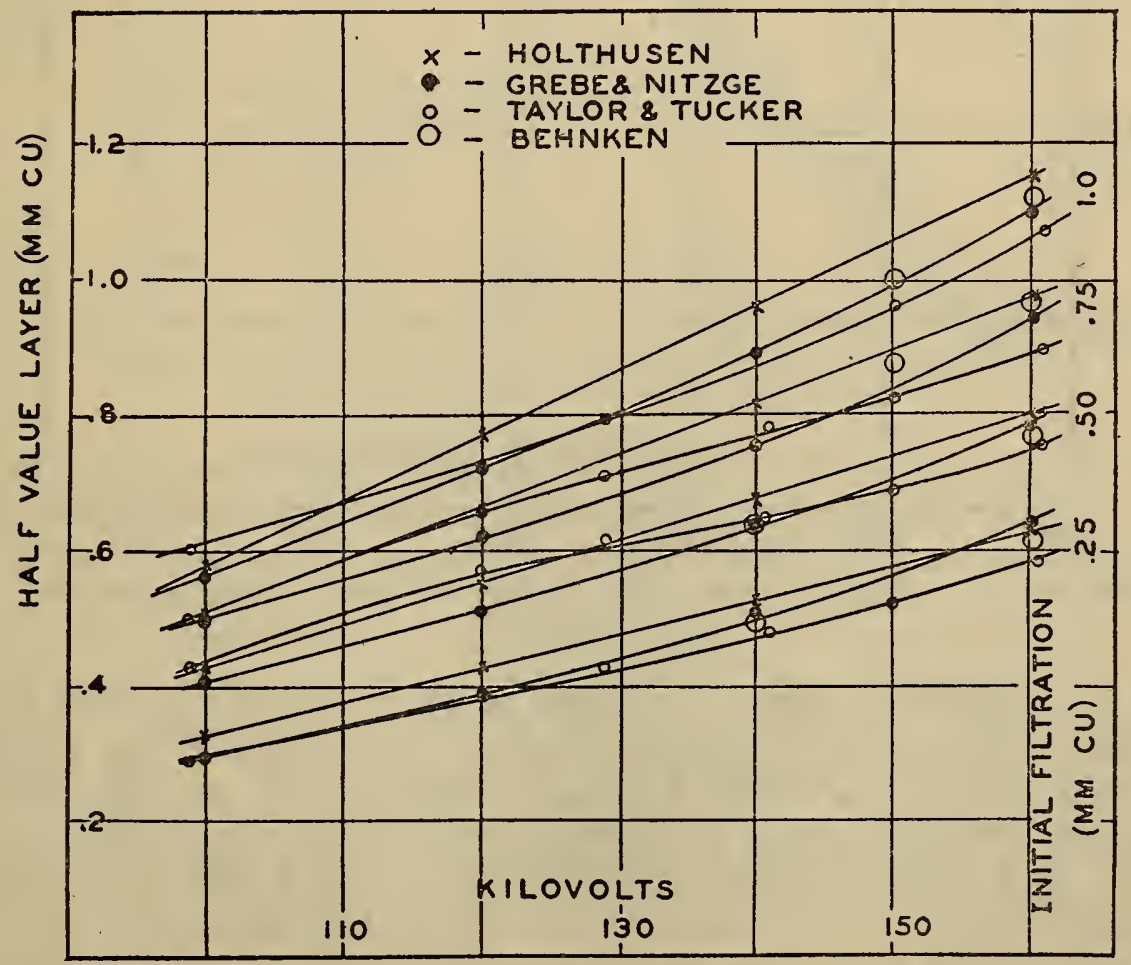

FIgURE 15.-Comparison of half-value layer measurements by different observers 
the effective voltage is considerably higher than the average. Figure 16 shows the relation between the peak and effective voltage for generators $A$ and $B$ used in this study. In order to produce the same total load on the rectifier as used in the previous experimentsthus having nearly the same wave form-the tube current was adjusted so that when added to that through the voltmeter $(0-1 \mathrm{ma})$ the total was $4 \mathrm{ma}$. Curves $A$ and $B$ are for generators $A$ and $B$, respectively, whence it may be seen that for the same peak voltage the two systems have quite different effective voltages.

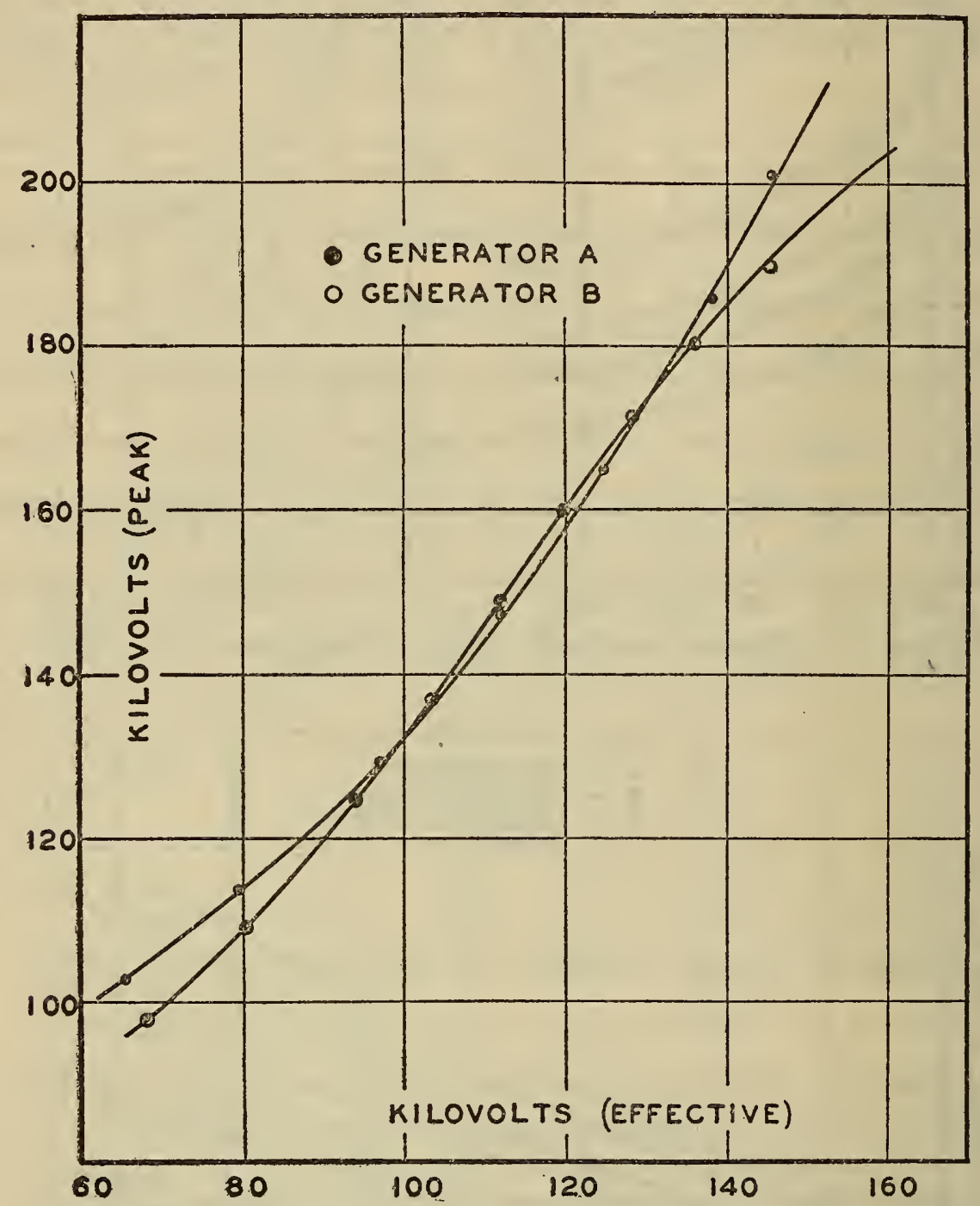

FIGURE 16.-Effective and peak voltage measurements on generators $A$ and $B$

That the effective voltage is more closely related to tube output than peak voltage may be readily seen. For example, for the same $200 \mathrm{kv}$ peak, generator $B$ had a greater output; and, as seen in Figure 16 , the effective voltage of $B$ exceeded that of $A$. Similarly, at 180 $\mathrm{kv}$.(peak) the outputs were approximately equal and it is likewise found that the effective voltages were about the same, and so on.

To compare the output of the three generators, when the potential is measured in effective kilovolts, the curve in Figure 17 shows the relationship between the beam intensity (filtered through $0.525 \mathrm{~mm}$. 
of copper) and the effective kilovoltage. Curve $C$ is for generator $C$ ("constant potential") and the other points are as indicated. It is seen at once that the output at a given voltage is of the same order of magnitude for all three generators. Since the radiation quality was found to be roughly proportional to the intensity for a given tube current, it follows that the effective voltage also presents a fairly close indication of the quality. These results will be discussed in greater detail in a later paper.

\section{CONCLUSION}

It is believed that any value to be ascribed to this study lies in showing physical similarities, and not differences, between high voltage $\mathrm{X}$-ray generators. Care has been taken to avoid any comparisons of the biological effectiveness per se of the radiations used. One of the outstanding biological problems is how to administer a desired

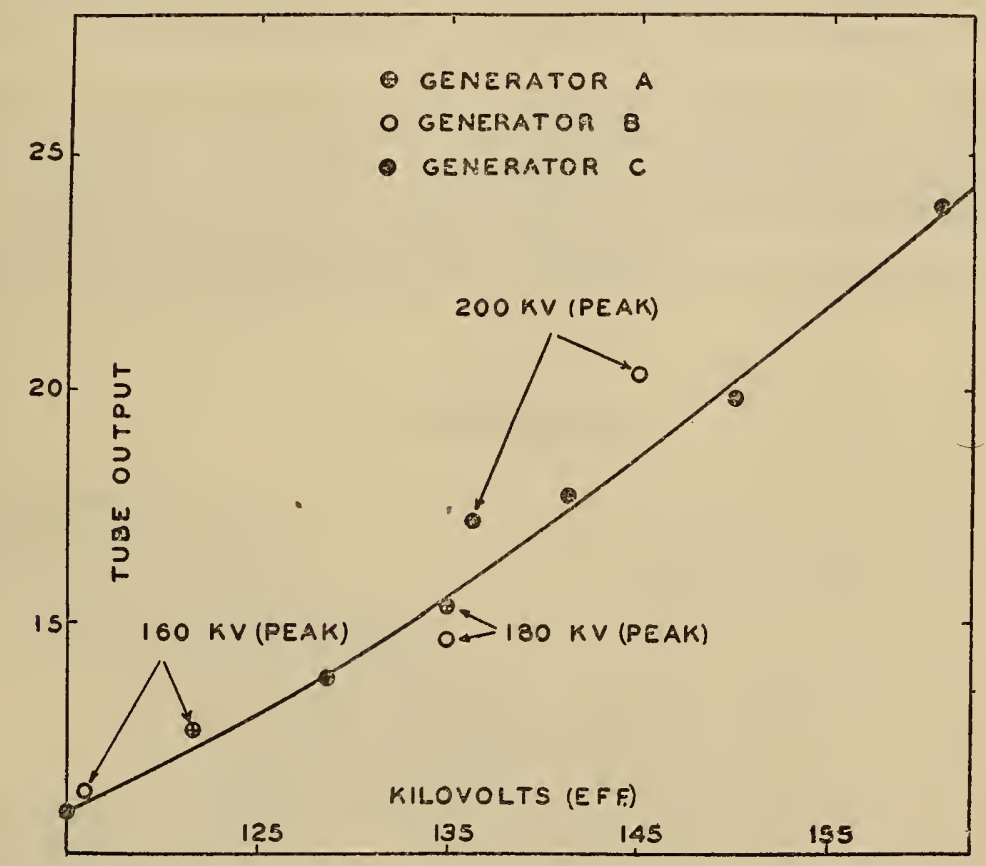

Figdre 17.- Plot showing tube output as a function of effective voltage for generators $A, B$, and $C$

dose of radiation within the body without at the same time producing a dangerous skin erythema or destroying intervening tissue. It has been shown here how equivalent depth dose may be obtained with different generators and a wide range of qualities and intensities. The clinical application of this wide range of radiations depends on two factors which must be decided by the clinician, not by the physicist. The first, is the relationship between quality and the erythema dose. The second is the economics of administering radiation, ${ }^{14}$ for obviously it would not be economical to use highly filtered low-voltage radiation for deep therapy when there is available a much greater intensity of less filtered radiation-assuming the biological effect to be the same. 
It is hoped that the results of the present study will enable the clinician to better compare his technique with that of others using different generators and making his measurements by different methods.

This study has been made possible through the support and the generous cooperation of the Radiological Research Institute and the X-ray manufacturers of this country, for which we express our appreciation. In addition, we thank G. Singer and C. F. Stoneburner, of this laboratory, for their assistance, particulary with the effective voltage measurements.

Washington, June 6, 1932. 